This is a peer-reviewed, accepted author manuscript of the following research article: Kwon, K. Y., Kang, J., \& Yun, J. (2021). Basis-momentum strategies and ranking periods. Finance Research Letters, [101997].

\title{
Basis-Momentum Strategies and Ranking Periods
}

\author{
Kyung Yoon Kwon ${ }^{\dagger}$, Jangkoo Kang, ${ }^{\ddagger}$ and Jaesun Yun*
}

\begin{abstract}
We analyze basis-momentum, the difference between the past 12 months' momentum in firstand second-nearby futures contracts suggested by Boons and Prado (2018). Since basis-momentum is related to the slope and the curvature over the ranking period, we split the 12-month ranking period into three subperiods - the current month, the past five months, and the six months before the previous five months - and construct three basis-momentums with them. Our results show that these three basis-momentums differ substantially in predicting future returns and have different economic determinants, namely, imbalance in the supply and demand and volatility risk in financial markets.
\end{abstract}

JEL classification: G10; G11; G12

Keywords: Commodity futures; Basis; Momentum; Basis-momentum; Term structure

\footnotetext{
${ }^{\dagger}$ Department of Accounting and Finance, Strathclyde Business School, University of Strathclyde, 199 Cathedral Street, Glasgow G4 0QU, UK; tel. +44-141-548-3935; e-mail arari1115@gmail.com.

* College of Business, Korea Advanced Institute of Science and Technology; 85 Hoegiro, Dongdaemoon-gu, Seoul, 02455, South Korea; e-mail: jkkang@kaist.ac.kr.

* Corresponding author; College of Business, Korea Advanced Institute of Science and Technology; 85 Hoegiro, Dongdaemoon-gu, Seoul, 02455, South Korea; e-mail: yjs16@kaist.ac.kr.
} 


\section{Introduction}

Boons and Prado (2018; hereafter BP) introduce basis-momentum, which is the difference between the past 12 months' momentum in first- and second-nearby futures contracts, and report its strong and robust return predictability in commodity futures markets. They employ a 12-month ranking period to measure momentum, following the conventional momentum literature. In this paper, we propose that the information content of basis-momentum could depend on the ranking period and its pricing effect could thus be variable.

We take note of the ranking period of basis-momentum, which has not yet been discussed in the literature, for three reasons. First, the momentum literature has consistently raised concern about the choice of the ranking period of the momentum (Nagel, 2012; Novy-Marx, 2012; Kang and Kwon, 2017). Second, previous studies have reported substantial differences between stock momentum and commodity futures momentum. ${ }^{1}$ We thus find an investigation of this approach in the commodity futures market, following the lead of stock market research, to be useful and necessary. Moreover, basismomentum considers another dimension in addition to simple momentum, and, therefore, whether the 12-month ranking period, the conventional choice in the momentum literature, is appropriate for this newly suggested variable becomes questionable.

Lastly and more importantly, an economic determinant of basis-momentum can differ depending on the ranking period. Previous studies on stochastic convenience yield suggest that the term-structure of commodity futures, especially the slope (basis), would be highly time varying. ${ }^{2}$ BP explain that their basis-momentum factor captures the change in the slope and average curvature of the commodity futures term-structure over the ranking period, which is the past 12 months. However, if the slope is

\footnotetext{
${ }^{1}$ For example, while Nagel (2012) reports strong reversal in the stock markets, Shen et al. (2007) and Kang and Kwon (2017) report that, in commodity futures markets, the one-month momentum is especially strong, as opposed to the findings from stock markets.

2 The literature has consistently highlighted the stochastic nature of the convenience yield, as well as stochastic commodity prices, and stochastic convenience yield has been generally adopted (Gibson and Schwartz, 1990; Cortazar and Schwartz, 1994; Schwartz, 1997; Miltersen and Schwartz, 1998; Casassus and Collin-Dufresne, 2005). This time-varying convenience yield has been generally proxied by the basis, the difference between the futures and spot prices or, intuitively, the slope of the futures term-structure, in the literature (Gibson and Schwartz, 1990; Schwartz, 1997; Trolle and Schwartz, 2009; Koijen et al., 2018).
} 
highly time varying or if various types of shocks cause change in the term-structure at higher frequencies, then 12-month basis-momentum would provide rather mixed information. Our motivation to investigate the ranking period of the basis-momentum is closely associated with concerns on the variety of the information content in historical movements of the term-structure and their relations with future returns, which can be sensitive to the choice of the ranking period.

In this paper, we split the past 12 months' ranking period into three subperiods and construct basis-momentums based on each of these ranking periods: the current month, the past five months, and the six months before the past five months. We first employ the current month motivated by the studies on the short-term reversal. ${ }^{3}$ The past five-month-period is employed following Novy-Marx (2012). Novy-Marx (2012) constructs two momentum strategies based on a firm's performance 12 to seven months prior to portfolio formation and one to six months prior to portfolio formation. The author empirically shows that the strategy based on the intermediate horizon-12 to seven months prior to portfolio formation - performs better, and similar results are observed in assets including commodity futures. Motivated by this finding, we further split the past 12-month-period into two subperiods, the past five months and the six months before the past five months.

To better understand the dynamics of the commodity futures term-structure and their effects on future returns, we investigate the possible economic sources of those three basis-momentums. BP report that the original 12-month basis-momentum is closely associated with imbalance in the supply and demand of futures contracts, and thus also related to volatility and liquidity risk. Our empirical results, however, suggest that the three basis-momentums based on different ranking periods represent different risks. Our findings suggest that the temporary imbalance in the supply and demand caused by the liquidity demand of speculators is mainly captured by the current month's basis-momentum, whereas that caused by hedgers' demand, which can be a more permanent shift in the imbalance, is captured by the past five months' basis-momentum. Lastly, the basis-momentum based on the six months before

\footnotetext{
${ }^{3}$ Specifically, in the short term, stocks that outperformed in the recent month exhibit strong reversal the subsequent month (Rosenberg et al., 1985; Jegadeesh, 1990; Lehmann, 1990; Nagel, 2012); empirical studies on stock momentum have therefore conventionally excluded the prior month from the ranking period.
} 
the previous five months, which shows much weaker predictability for the future returns of commodity futures, is significantly related to the equity market or volatility risk.

\section{Data and variables}

We obtain data on 21 US commodity futures contracts, including daily settlement prices, from January 1979 to December 2017 from Datastream. ${ }^{4}$ We compute monthly excess returns on fully collateralized futures positions. To compute the return in month $t+1$, we take a position in the futures contract whose maturity is after the end of month $t+1$ at the end of month $t$. Following Szymanowska et al. (2014) and BP, we construct two types of returns: the nearby return (spot premium) is obtained by taking a long position in the first-nearby contract, and the spreading return (term premium) is obtained by taking a long position in the first-nearby contract and a short position in the second-nearby contract.

Following BP, the basis, momentum, and basis-momentum $\left(B M\left(k_{1}, k_{2}\right)_{t}\right)$ are defined as follows, respectively:

$$
\begin{aligned}
& \text { Basis }_{t}=\frac{F_{t}^{T_{2}}}{F_{t}^{T_{1}}}-1 \text { and } \text { Momentum }_{t}=\prod_{s=t-11}^{t}\left(1+R_{f u t, s}^{T_{1}}\right)-1 \text {, } \\
& B M\left(k_{1}, k_{2}\right)_{t}=\prod_{s=t-k_{1}}^{t-k_{2}}\left(1+R_{f u t, s}^{T_{1}}\right)-\prod_{s=t-k_{1}}^{t-k_{2}}\left(1+R_{f u t, s}^{T_{2}}\right),
\end{aligned}
$$

where for month $t, F_{t}^{T_{i}}$ indicates the $i$ th-nearby futures price and $R_{f u t, t}^{T_{i}}$ indicates $i$ th-nearby futures returns. In addition to the original basis-momentum $\left(B M(11,0)_{t}\right)$ suggested by $\mathrm{BP}$, we construct three basis-momentums based on three different ranking periods: the current month $(B M(0,0))$; the previous

\footnotetext{
${ }^{4}$ Our data cover four major categories of commodities: agriculture, energy, livestock, and metal. Specifically, we include commodity futures contracts on feeder cattle, live cattle, corn, lean hogs, random length lumber, oats, rough rice, soybeans, soybean meal, soybean oil, wheat, cocoa, coffee $\mathrm{C}$, cotton no. 2, frozen concentrated orange juice, light crude oil, heating oil, RBOB gasoline, high-grade copper, gold, and silver.
} 
five months, from month $t-5$ to $t-1(B M(5,1))$; and the six months before the previous five months, that is, from month $t-11$ to $t-6(B M(11,6))$.

Using the logarithmic transformation approach suggested by BP, the original basis-momentum can be decomposed into the change in the slope and the average curvature at higher frequencies, as follows:

$$
\begin{aligned}
\sum_{s=t-11}^{t} r_{f u t, s}^{1}-\sum_{s=t-11}^{t} r_{f u t, s}^{2}=\sum_{s=t-11}^{t} b_{s-1}^{2}-\sum_{s=t-11}^{t} b_{s}^{1}=\left(\sum_{s=t-11}^{t-1} b_{s}^{2}-\sum_{s=t-11}^{t-1} b_{s}^{1}\right)+\left(b_{t-12}^{2}-b_{t}^{1}\right) \\
=\left\{\left(\sum_{s=t-11}^{t-7} b_{s}^{2}-\sum_{s=t-11}^{t-7} b_{s}^{1}\right)+\left(b_{t-12}^{2}-b_{t-6}^{1}\right)\right\}+\left\{\left(\sum_{s=t-5}^{t-2} b_{s}^{2}-\sum_{s=t-5}^{t-2} b_{s}^{1}\right)+\right. \\
\left.\quad\left(b_{t-6}^{2}-b_{t-1}^{1}\right)\right\}+\left(b_{t-1}^{2}-b_{t}^{1}\right),
\end{aligned}
$$

where the first term $\left(\left(\sum_{s=t-11}^{t-7} b_{s}^{2}-\sum_{s=t-11}^{t-7} b_{s}^{1}\right)+\left(b_{t-12}^{2}-b_{t-6}^{1}\right)\right)$ indicates the basis-momentum from month $t-11$ to $t-6$ and the second term $\left(\left(\sum_{s=t-5}^{t-2} b_{s}^{2}-\sum_{s=t-5}^{t-2} b_{s}^{1}\right)+\left(b_{t-6}^{2}-b_{t-1}^{1}\right)\right)$ indicates the basis-momentum from month $t-5$ to $t-1$. The last term $\left(b_{t-1}^{2}-b_{t}^{1}\right)$ indicates the current month basis-momentum.

Based on this decomposition, we can see that the current month's basis-momentum includes only the change in slope component whereas the other two basis-momentums include both change in slope and average curvature components. It also shows that these three basis-momentums embody information about the futures term-structure in the separate periods.

\section{Return predictability and pricing effects of basis-momentums}

We first investigate the return predictability of the basis-momentums with the three different ranking periods by constructing univariate-sorted tercile portfolios. In each month, we sort the 21 commodities into three portfolios: High4 (Low4) includes the four commodities with the highest (lowest) ranked signal and Mid includes the remaining commodities. Panels A and B of Table 1 report the average nearby and spreading returns on portfolios, respectively. 
[Insert Table 1 about here]

Table 1 shows substantial differences across the three basis-momentums with different ranking periods. Panel A shows that the High4-minus-Low4 (H-L) $B M(0,0)$ and $B M(5,1)$ portfolios generate large and significant average nearby returns, whereas that of $B M(11,6)$ does not. In Panel $\mathrm{B}, B M(0,0)$ shows an insignificant difference in spreading returns between High4 and Low4, whereas the other two basis-momentums show significantly positive differences. BP highlight that curvature plays an essential role in predicting spreading returns, so this result could be because $B M(0,0)$ contains only the change in slope. The High4-minus-Low4 $B M(5,1)$ portfolio generates a large and significant spreading return that is even comparable to that of the original basis-momentum. The High4-minus-Low4 $B M(11,6)$ portfolio also generates a significant spreading return, but it is much smaller than that of $B M(5,1)$.

Next, we examine the pricing effect of the three basis-momentums after controlling for other variables by regressing individual commodity futures returns on the basis-momentums and control variables, following Fama and MacBeth (1973). Panels A and B of Table 2 present the results for the nearby and spreading returns, respectively.

\section{[Insert Table 2 about here]}

Models (1) and (2) in Table 2 confirm BP's finding that the original basis-momentum is significantly priced, even after controlling for the basis and momentum. Models (3) to (5) in Panel A show that the three basis-momentums are significantly priced without control variables. However, after controlling for other effects, Models $(6)$ to $(8)$ show that $B M(0,0)$ and $B M(11,6)$ become insignificant, whereas $B M(5,1)$ remains highly significant. Models (3) to (5) in Panel B show that the basismomentums except $B M(0,0)$ are significantly priced, consistent with Table 1. As in Panel A of Table 2 , even for spreading returns, $B M(5,1)$ shows the most significant results.

Overall results support our motivation to split the original ranking period of BP's basismomentum. The three basis-momentums show substantial differences in the relations with the basis and momentum, as well as with expected returns. In untabulated results, we also confirm that the three basis- 
momentums cannot span each other, which implies that they could play different roles in shaping risks in the commodity futures market.

\section{Economic interpretation}

In this section, we explore the economic sources of the three basis-momentums with different ranking periods. First, we analyze the relation between the three basis-momentums and the positions of traders focusing on a commodity-specific feature, following BP. Second, we examine whether the three basis-momentum returns can be accounted for by various market-wide factors.

\subsection{Traders' positions}

To examine the relation between traders' positions and basis-momentum returns, we use data from the Commitment of Traders' weekly reports provided by the Commodity Futures Trading Commission and construct the hedging pressure $(H P)$ and spreading pressure $(S P)$ variables. ${ }^{5}$ To examine the interactive effects of hedging (spreading) pressure and basis-momentum, we run the following Fama-MacBeth regression:

$$
\begin{gathered}
R_{f u t, i, t+1}^{h}=a_{t+1}+\lambda_{B M} B M\left(k_{1}, k_{2}\right)_{i, t}+\lambda_{H P} I_{H P, i, t}+\lambda_{S P} I_{S P, i, t}+\lambda_{H P B M}\left(I_{H P, i, t} \times B M\left(k_{1}, k_{2}\right)_{i, t}\right)+ \\
\lambda_{S P B M}\left(I_{S P, i, t} \times B M\left(k_{1}, k_{2}\right)_{i, t}\right)+e_{i, t+1} \quad \text { for } h=\{n b, s p r\}
\end{gathered}
$$

\footnotetext{
${ }^{5}$ The Commitment of Traders' reports provide weekly position data that include open interests, the number of short and long positions, and the number of spreading positions of each of three trader groups-commercial, noncommercial, and nonreportable - aggregated at the commodity level. Following the literature, we consider commercial traders hedgers, and noncommercial traders speculators. Then, based on these weekly position data, following Kang et al. (2020) and BP, we construct the hedging pressure variable (HP), which is defined as the past 12 months' average of the difference between the number of short and long positions of commercial traders divided by the open interest. Following BP, we also construct the spreading pressure variable $(S P)$, which is defined as the three-month average of the number of noncommercial spreading positions divided by the open interest. Due to data availability, the sample in this section is restricted to the period from January 1986 to December 2017.
} 
where $R_{f u t, i, t+1}^{h}$ for $h=n b$ or $h=s p r$ indicates a commodity futures nearby or spreading return, respectively, and $I_{H P, i, t}\left(I_{S P, i, t}\right)$ is a dummy variable that is equal to one when $H P(S P)$ of commodity $i$ in month $t$ is above the time-series median of the commodity, and zero otherwise. ${ }^{6}$

\section{[Insert Table 3 about here]}

In Table 3, the coefficients of the basis-momentums show dramatic changes from considering the interactive effects with the traders' positions, compared to the results in Table 2. For both nearby and spreading returns, $B M(5,1)$ shows insignificant coefficients, but the two interaction terms appear to be significantly priced indicating that $B M(5,1)$ significantly predicts future nearby and spreading returns only if $H P$ or $S P$ is relatively high.

Interestingly, with respect to the interactive effects with $H P, B M(0,0)$ and $B M(5,1)$ reveal the opposite results. $B M(0,0)$ positively predicts future returns only when hedging pressure is relatively low, whereas $B M(5,1)$ does so only when hedging pressure is relatively high. BP document that basismomentum is closely associated with imbalance in the supply and demand of futures contracts over the ranking period. If their interpretation is correct, $B M(0,0)(B M(5,1))$ should then be related to shortterm (intermediate-term) imbalance in supply and demand. Kang et al. (2020) note two types of risk premia in commodity futures markets: one related to the liquidity demands of impatient speculators and the other related to the hedging demand of hedgers. The authors empirically show that speculator demand is observed from short-term position change, whereas hedger demand is observed from longterm position change, and these are priced with opposite signs. Collectively, if $B M(0,0)(B M(5,1))$ captures the short-term (intermediate-term) imbalance due to speculator (hedger) demand, then the premium for providing liquidity to them would be higher when hedging pressure is low (high). ${ }^{7}$ In that

\footnotetext{
${ }^{6}$ BP consider that this dummy specification allows the results to be less affected by Commodity Futures Trading Commission classification issues and accommodate the interpretation of the interaction effects.

${ }^{7}$ Specifically, hedging pressure can be interpreted in two ways. If hedgers actively require short positions to hedge their spot price risk, then this would indicate the hedging demand consuming liquidity in the market. By contrast, when speculators more actively take long positions, then hedging pressure will capture the passive short position of hedgers, which indicates hedgers' liquidity provision in the market.
} 
sense, our result that the return on $B M(0,0)(B M(5,1))$ becomes higher when hedging pressure is relatively low (high) seem to be consistent with the argument of Kang et al. (2020).

BP suggest that, in times of high uncertainty, speculators are averse to directional positions and thus prefer spreading positions. If $B M(5,1)$ is associated with imbalance in the supply and demand due to hedger demand, then the positive coefficients on $I_{S P} \times B M(5,1)$ indicate greater compensation for taking such risks. If $I_{S P}$ captures the state in which speculators are more risk averse, requiring a larger risk premium, and $B M(5,1)$ captures the large hedging demand, then their interaction term could capture the larger premium caused by these two effects, the larger compensation for the risk, and the larger risk itself.

Lastly, $B M(11,6)$ shows insignificant interaction effects in most cases. The results reveal only one exception (coefficient on $I_{S P} \times B M(11,6)$ for nearby returns), but it is significant only at the $10 \%$ level and even has a negative sign, while BP report a positive interaction effect of the original basismomentum and spreading pressure.

\subsection{Market-wide factors and basis-momentum returns}

In this section, we investigate the relation between basis-momentum returns and market-wide factors - volatility, liquidity, and financial intermediary risks — following Bakshi et al. (2019). For volatility, we consider commodity futures market volatility $\left(\Delta V O L_{t}^{m k t}\right)$ and equity market volatility $\left(\Delta V X O_{t}\right) .{ }^{8}$ Since we consider the volatility risk of the equity market, we also include the equity market risk $(M K T) .{ }^{9}$ For funding liquidity risk, we use the change in the spread between the three-month London Interbank Offered Rate (LIBOR) and the three month US T-bill rate $\left(\triangle T E D_{t}\right)$ and the change

\footnotetext{
${ }^{8}$ For the commodity futures market volatility, we compute aggregate commodity market variance in month $t$, $V O L_{t}^{m k t}$, as the sum of squared daily (nearby) returns on an equal-weighted commodity portfolio following BP. Then, the commodity market volatility risk factor is defined as the first-difference in the market variance, $\triangle V O L_{t}^{m k t}$. For the equity market volatility, we use the implied volatility of S\&P 100 index options (VXO) and compute the equity market volatility risk factor as the first-difference in the VXO, $\triangle V X O_{t}$.

${ }^{9}$ For the equity market risk, we employ the Center for Research in Security Prices value-weighted excess return.
} 
in spread between the three-month certificate of deposit and the US T-bill rate $\left(\triangle C D T B_{t}\right)$. Lastly, for intermediary risk, we use the financial intermediary risk factor $(F I R)$ constructed by He et al. (2017). ${ }^{10}$

Following Bakshi et al. (2019), for each risk factor, we first run a time-series regression of each basis-momentum portfolio return on the risk factor to estimate the coefficient (or beta) on it. Then, we run a cross-sectional regression of a set of portfolio returns (High4, Mid, and Low4) on the estimated beta; ${ }^{11}$ that is, we investigate whether the three basis-momentum returns can be accounted for by market-wide risks.

[Insert Table 4 about here]

In Table 4, for each set of basis-momentum portfolios (High4, Mid, and Low4, formed on each of the basis-momentums), we report the pricing effects of six variables estimated separately. The original basis-momentum shows significant relations with volatility risks, $\triangle V O L_{t}^{m k t}$ and $\triangle V X O_{t}$, for both nearby and spreading returns. However, if we construct the basis-momentums with different ranking periods, we can see substantial differences in the relations with the market-wide factors across the basis-momentums. For the premia on $B M(0,0)$ and $B M(5,1)$, for which we find a significant link with the imbalance of supply and demand in the commodity market, our results in Table 4 show no significant relation with market-wide risks, with one exception (the spreading return on $B M(5,1)$ ). By contrast, $B M(11,6)$, which shows no significant relation in Table 3 , reveals some differences. Specifically, our results suggest that $B M(11,6)$ embodies substantial information about market volatility. Both the commodity market and equity market volatility factors are negatively and significantly priced in both the spot and term premia. Compared to the other basis-momentums, $B M(11,6)$ especially shows a strong relation with them. The equity market factor $(M K T)$ also shows a marginally significant relation with the term premia on $B M(11,6)(\mathrm{t}$-statistics $=-1.82)$. Considering that $B M(11,6)$ generally exhibits nonsignificant interaction effects with hedging and spreading

\footnotetext{
${ }^{10}$ See http://apps.olin.wustl.edu/faculty/manela/data.html.

${ }^{11}$ We include the commodity futures market factor in all models as a control variable following Bakshi et al. (2019) and BP, but we do not report the coefficients on the commodity market factor for brevity.
} 
pressure in Table 3 , the overall results suggest that $B M(11,6)$ is closely associated with financial market states.

\section{Conclusion}

Motivated by the dynamic nature of the basis, the term-structure of futures, we construct three basis-momentums with different ranking periods - the current month, the past five months, and the six months before the previous five months - and find that the three basis-momentums with those ranking periods are related to different economic determinants. We expect our findings to improve the understanding of the dynamics of the commodity futures term-structure and their effects on future returns. 


\section{References}

Bakshi, G., Gao, X., Rossi, A.G., 2019. Understanding the sources of risk underlying the cross section of commodity returns. Management Science 65, 619-641.

Boons, M., Prado, M.P., 2018. Basis-momentum. Journal of Finance 74, 239-279.

Casassus, J., Collin-Dufresne, P., 2005. Stochastic convenience yield implied from commodity futures and interest rates. Journal of Finance 60, 2283-2331.

Cortazar, G., Schwartz, E.S., 1994. The valuation of commodity-contingent claims. Journal of Derivatives 1, 27-39.

Fama, E.F., MacBeth, J., 1973. Risk, return and equilibrium: empirical tests. Journal of Political Economy 51, 55-84.

Gibson, R., Schwartz, E.S., 1990. Stochastic convenience yield and the pricing of oil contingent claims. Journal of Finance 45, 959-976.

He, Z., Kelly, B., Manela, A., 2017. Intermediary asset pricing: New evidence from many asset classes. Journal of Financial Economics 126, 1-35.

Jegadeesh, N., 1990. Evidence of predictable behavior of security returns. Journal of Finance 74, 239-279.

Kang, J., Kwon, K.Y., 2017. Momentum in international commodity futures markets. Journal of Futures Markets 37, 803-835.

Kang, W., Rouwenhorst, K.G., Tang, K., 2020. A tale of two premiums: The role of hedgers and speculators in commodity futures markets. Journal of Finance 75, 377-417.

Koijen, R.S.J., Moskowitz, T.J., Pedersen, L.H., Vrugt, E.B., 2018. Carry. Journal of Financial Economics 127, 197-225.

Lehmann, B.N., 1990. Fads, martingales, and market efficiency. Quarterly Journal of Economics $105,1-28$.

Miltersen, K.R., Schwartz, E.S., 1998. Pricing of options on commodity futures with stochastic term structure of convenience yields and interest rates. Journal of Financial and Qualitative Analysis 33, 33-59.

Nagel, S., 2012. Evaporating liquidity. Review of Financial Studies 25, 2005-2039.

Novy-Marx, R., 2012. Is momentum really momentum? Journal of Financial Economics 103, 429 453.

Rosenberg, B., Reild, K., Lanstein, R., 1985. Persuasive evidence of market inefficiency. Journal of Portfolio Management 11, 9-16.

Schwartz, E.S., 1997. The stochastic behavior of commodity prices: Implications for valuation and hedging. Journal of Finance 52, 923-973. 
Shanken, J., 1992. On the estimation of beta-pricing models. Review of Financial Studies 5, 1-33.

Shen, Q., Szakmary, A.C., Sharma, S.C., 2007. An examination of momentum strategies in commodity futures markets. Journal of Futures Markets 27, 227-256.

Szymanowska, M., de Roon, F., Nijman, T., van den Goorbergh, R., 2014. An anatomy of commodity futures risk premia. Journal of Finance 69, 453-482.

Trolle, A.B., Schwartz E.S., 2009. Unspanned stochastic volatility and the pricing of commodity derivatives. Review of Financial Studies 22, 4423-4461. 